\title{
El endeudamiento público excesivo como factor de ineficacia del derecho humano a un buen gobierno*
}

\author{
Gustavo González Galindo** \\ Recibido: 27 de febrero de 2018 • Aprobado: 07 de mayo de 2018 \\ https://doi.org/10.22395/ojum.v17n34a10
}

\begin{abstract}
RESUMEN
El ser humano siempre ha aspirado a tener mejores condiciones de vida, por lo que, a través de las diversas formas de organización política que se han creado para tal fin, se considera que el buen gobierno constituye un derecho humano consistente, entre diversas tareas, en la eficiente administración de los recursos públicos. En este sentido, la administración pública también se considera un derecho humano, dado que constituye una de las principales vías para la satisfacción de otros derechos humanos. Desafortunadamente, en la realidad mexicana se ha venido observando con mayor frecuencia un excesivo endeudamiento subnacional, que generalmente es producido por una ineficiente administración pública, lo que propicia una disminución presupuestaria de los recursos que serán destinados a la satisfacción de otros derechos humanos, lo que tiene como efecto colateral que a estos derechos no se les hayan desarrollado mecanismos de control ni medición. El objetivo de este trabajo consiste en subrayar los avances que han surgido en Ciudad de México en materia de eficacia de derechos humanos a través de un caso de disminución presupuestaria del metrobús que, seguramente con base en la metodología del Alto Comisionado de las Naciones Unidas, servirá para elaborar indicadores que abonen al desarrollo de esta nueva etapa de los derechos humanos.
\end{abstract}

Palabras clave: derechos humanos; derecho a un buen gobierno; finanzas públicas; eficacia jurídica; indicadores.

Este artículo es resultado de la investigación realizada dentro del programa de apoyo a la incorporación de nuevos profesores de tiempo completo, bajo el proyecto del mismo título, con financiamiento del programa para el desarrollo profesional docente de la Secretaría de Educación Pública, participó el autor como único responsable.

3 Licenciado en Derecho, Universidad Veracruzana, Veracruz, México; doctor en Derecho Público, Universidad Veracruzana; profesor de asignatura en la Facultad de Derecho de la Universidad Veracruzana; investigador nacional nivel 1 del Sistema Nacional de Investigadores del Conacyt. Líder del Cuerpo Académico Eficacia Jurídica y Derechos Humanos. Correo electrónico: gusgon3@live.com.mx. Orcid: 0000-0002-8189-1751. 


\title{
Excessive public indebtedness as a factor of ineffectiveness of the human right to good governance
}

\begin{abstract}
The human being has always aspired to have better living conditions, so that, through the various forms of political organization that have been created for this purpose, it is considered that good governance is a human right consistent, among various tasks, in the efficient administration of public resources. In this sense, public administration is also considered a human right, since it constitutes one of the main ways to satisfy other human rights. Unfortunately, in the Mexican reality an excessive subnational indebtedness has been observed with greater frequency, which is generally produced by an inefficient public administration, which propitiates a budgetary decrease of the resources that will be destined to the satisfaction of other human rights, having as collateral effect that these rights have not been developed mechanisms of control nor measurement. The aim of this work is to highlight the progress made in Mexico City in the area of human rights effectiveness through a case of a reduction in the budget for metrobuses which, probably based on the methodology of the Office of the United Nations High Commissioner for Human Rights, will be used to develop indicators that will contribute to the development of this new stage of human rights.
\end{abstract}

Keywords: human rights; right to good governance; public finances; legal effectiveness; indicators.

\section{0 endividamento público excessivo como fator de ineficácia do direito humano para um bom governo}

\section{RESUMO}

O ser humano sempre desejou ter melhores condições de vida e, por isso, por meio das diversas formas de organização política que foram criadas para essa finalidade, considera-se que o bom governo constitui um direito humano consistente, entre várias tarefas, na eficiente administração dos recursos públicos. Nesse sentido, a administração pública também é considerada um direito humano, visto que constitui uma das principais vias para a satisfação de outros direitos humanos. Infelizmente, vem-se observando com maior frequência um excessivo endividamento subnacional na realidade mexicana, que geralmente é produzido por uma ineficiente administração pública, o que propicia uma diminuição orçamentária dos recursos que serão destinados à satisfação de outros direitos humanos, tendo como um efeito colateral o fato de que não tenham sido desenvolvidos mecanismos de controle nem medição para esses direitos. O objetivo desse trabalho consiste em destacar os avanços que surgiram na cidade do México em matéria de eficácia de direitos humanos mediante um caso de diminuição orçamentária do metrobus que, seguramente com base na metodologia do Alto Comissionado das Nações Unidas, servirá para elaborar indicadores que colaborem para o desenvolvimento dessa nova etapa dos direitos humanos.

Palavras-chave: direitos humanos; direito a um bom governo; finanças públicas; eficácia jurídica; indicadores. 


\section{INTRODUCCIÓN}

Desde tiempos inmemoriales, el ser hu mano se unió con otros semejantes para alcanzar objetivos comunes de sobrevivencia, como la caza, la alimentación, la protección entre sí y de otros semejantes ajenos al grupo social, etc., para lo cual fue necesario establecer reglas básicas de organización. Desde entonces se vislumbran los primeros indicios del derecho humano a una administración social, que posteriormente evolucionó y hoy se conoce como el derecho a un buen gobierno, que se apoya en gran medida en una buena administración pública, considerada como otro derecho humano.

Estos derechos humanos han sido reconocidos en múltiples documentos jurídicos de índole internacional que han permeado los ordenamientos constitutivos de la mayoría de los Estados que actualmente se consideran democráticos. No obstante lo anterior, el derecho humano a un buen gobierno, que incluye el derecho a una buena administración pública, ha sido poco explorado, en razón de que, históricamente, los gobiernos no rendían cuentas de sus actos y solo hasta las últimas décadas del siglo XX, una vez que se había conquistado la primera etapa de reconocimiento de derechos humanos, comenzó a cuestionarse el cumplimiento de tantos derechos previamente reconocidos, dando paso a la etapa de la medición de su eficacia.

Los organismos internacionales protecto res de derechos humanos, encabezados por el Alto Comisionado de las Nacio- nes Unidas para los Derechos Humanos (ACNUDH), fueron los precursores en proponer metodologías para la medición del cumplimiento de derechos, sustentados básicamente en la creación de indicadores para cada derecho en particular, en virtud de que cada derecho humano tiene condiciones específicas de aplicación y efectividad, esto es, en el derecho al estudio es innegable que cada gobierno tiene condiciones particulares de población, clima, economía, legislación, recursos naturales, historia, etc., por lo que se requieren indicadores específicos para medir su grado de cumplimiento.

La función gubernamental tiene diversas actividades para alcanzar la finalidad estatal que consiste en el bien público temporal (Porrúa, 1990, p. 190). Entre las que se encuentran las de proveer de alimentación, salud, seguridad, educación, vivienda, transporte y, en general, propiciar todas aquellas condiciones que lleven a los integrantes de la sociedad a alcanzar las mejores condiciones de vida, para lo cual debe, en primer término, contar con finanzas públicas sanas que le permitan tener recursos para la implementación de aquellas condiciones.

En este sentido, el creciente endeudamiento de diversas entidades federativas en México es reflejo de que no cuentan con finanzas públicas sanas, lo que produce, como consecuencia inmediata, la disminución de recursos para el desarrollo progresivo de los derechos económicos, sociales y culturales (DESC); por lo que habiendo identificado a Ciudad de México (CDMX) como la entidad federativa (EF) 
más endeudada del país, que además es también la más poblada, se decidió tomar como punto de referencia la metodología propuesta por el ACNUDH, a fin de que dicha EF alcance los avances en materia de efectividad jurídica que sus ordenamientos locales han vislumbrado. A fin de materializar lo anterior, se ha observado la forma en que ha impactado el endeudamiento en los presupuestos de egresos de la CDMX, tomando como rubro específico el presupuesto asignado al metrobús, en virtud de que se trata de una de las necesidades más apremiantes por su gran población, aunado a que también ha sido de las más afectadas presupuestalmente.

Con base en lo anterior, se tiene la razonable seguridad de que la disminución presupuestaria ha impactado negativamente en el nivel del servicio a la población, dado que cada año aumenta la población y se tiene que satisfacer la movilidad con menos recursos, por lo que al utilizar la metodología del ACNUDH, con toda seguridad se llegarán a formular y a proponer los indicadores que midan la eficacia del buen gobierno, bajo el rubro específico del metrobús, a la vez que serán los primeros indicadores que se proponen para la medición de este derecho humano.

\section{DERECHO HUMANO A UN BUEN GOBIERNO}

Desde antes de la aparición del Estado, los seres humanos ya se agrupaban para sobrevivir, sin embargo, ante los prepotentes y arbitrarios actos de sus semejantes ${ }^{1}$ surgió la necesidad de estudiar y

Esta característica humana deriva de las corrientes tanto optimistas como pesimistas aludidas discutir la naturaleza, función, finalidad y alcance de sus derechos, toda vez que, al no existir normas jurídicas en los primeros colectivos humanos que regularan su conducta, prevalecía la ley de la naturaleza (entendida como la ley del más fuerte), que se caracterizaba por los abusos y opresiones que desde entonces se han dado entre los seres humanos ${ }^{2}$.

No obstante los miles de años que tiene el hombre estudiando sus derechos, la tarea no ha sido fácil ni conclusiva, al grado que hoy en día no se ha llegado a un consenso sobre la denominación más adecuada para ellos y se han propuesto a lo largo de la historia, y de acuerdo a diversas ideologías, denominaciones como derechos humanos, derechos naturales, derechos públicos subjetivos, libertades públicas, derechos morales y derechos fundamentales ${ }^{3}$, de donde se desprenden otras discusiones de no menor importancia, como las relativas al surgimiento, determinación, limitación y clasificación.

Discrepancias como las anteriores han propiciado que en la actualidad, a pesar de los avances en esta materia, prevalezcan problemas de interpretación, aplicación y cumplimiento de normas de derechos humanos, dado que, si bien es

por Óscar Correas en su libro Introducción a la sociología jurídica.

2 Tal afirmación encuentra sustento en la frase homo homini lupus, popularizada en la obra El Leviatán de Thomas Hobbes, al afirmar que el hombre es el lobo del propio hombre.

3 Sirvan de ejemplo las principales denominaciones analizadas por Gregorio Peces-Barba (1999), en su libro Curso de derechos fundamentales. 
cierto que hoy en día un gran número de autoridades no tienen inconvenientes en reconocer largas listas de derechos humanos, también lo es que, paradójicamente, existen graves inconsistencias sobre su cumplimiento y eficacia, lo que conduce a una serie de conflictos como el que ha motivado la presente investigación, consistente en la ineficiente administración de las finanzas públicas que genera un endeudamiento gubernamental al no existir congruencia entre los ingresos y los gastos, lo que se refleja en la disminución presupuestaria para solventar diferentes derechos humanos, dando lugar a la insatisfacción del derecho humano a un buen gobierno (en adelante, DHBG).

Con el fin de conocer el DHBG, es necesario realizar un somero estudio de los derechos humanos, siendo pertinente y recomendable hacerlo a través del sistema diacrónico ${ }^{4}$, que abarca tanto los acontecimientos históricos, como las corrientes filosóficas surgidas a lo largo de la historia de la humanidad que se han conjugado para culminar en ordenamientos jurídicos, en razón que el ámbito histórico de los derechos se ha entendido como:

\begin{abstract}
Una formalización de los materiales aportados por la historia, que explican el origen de los derechos en el tiempo, las condiciones sociales, económicas, culturales y políticas que les originan como idea moderna de la dignidad humana, y los ámbitos y circunstan-
\end{abstract}

$4 \quad$ Esta manera de estudiar los derechos humanos fue propuesta por Gregorio Peces-Barba en su libro Curso de derechos fundamentales, con el fin de evitar reduccionismos. cias en que surge. (Peces-Barba, 1999, p. 106).

En este sentido, los hechos históricos sentaron las condiciones político-socio-económicas que favorecieron el surgimiento de pensadores, que a su vez propiciaron otros acontecimientos, y en la mayoría de los casos fueron plasmados en instrumentos preponderantemente jurídicos, que al haberse desarrollado paralelamente a los hechos, corrientes filosóficas y derecho, se formó una espiral hasta nuestros días que ha producido información útil para la construcción de la actual teoría de los derechos humanos.

Atendiendo al objetivo del presente trabajo, que no aspira ser un estudio monográfico de los derechos humanos, se citarán los acontecimientos más representativos que han servido de base para sustentar que la eficiente administración de un gobierno constituye un derecho humano. En este sentido, existe suficiente evidencia para afirmar que el origen y evolución de los derechos humanos han tenido un desarrollo similar en todos los pueblos de la tierra, comenzando desde el momento en que el hombre se hallaba en el estado de naturaleza, donde prevalecía la ley del más fuerte, dado que "todos los hombres se hallan naturalmente en aquel estado y en él permanecen hasta que, por su propio consentimiento, se hacen miembros de alguna sociedad política" (Locke, 2005, p. 9). Posteriormente, el ser humano decidió establecer una sociedad formal con la finalidad de salir del abuso de sus semejantes más fuertes, buscando tutelar 
su vida, familia y patrimonio, por lo que estableció algunas reglas de convivencia, cambiando el estado de naturaleza por el de derecho ${ }^{5}$, lo que posteriormente se afirmó al señalar que "el orden social constituye un derecho sagrado que sirve de base a todos los demás. Sin embargo, este derecho no es un derecho natural: está fundado sobre convenciones" (Rousseau, 2006, p. 4).

Con base en lo anterior se ha afirmado que las primeras sociedades consideradas primitivas, porque no contaban con una forma de gobierno bien establecida, no reconocían derechos humanos, por lo que paulatinamente fueron evolucionando y desarrollando incipientes "sistemas absolutistas de gobierno de corte monárquico, imperial y en general, todas aquellas formas que implican la unificación del poder en una sola persona, con gran influencia teocrática" (González, 2013, p. 4). Lo anterior encuentra sustento en las culturas más antiguas de las que el hombre tiene datos registrados, como la egipcia, la babilónica, o incluso en otros hemisferios de la tierra como el pueblo chino, el japonés, los aztecas o los incas que, a su vez, continuaron organizándose para protegerse de los abusos y arbitrariedades de sus monarcas, llegando a limitarlos a través de algunos ordenamientos.

Con las mismas características, pero un poco más desarrollada, continuó la Edad

5 Tal cambio de concepción del estado de naturaleza al de derecho, se puede apreciar con mayor detalle en el libro La ponderación de los derechos fundamentales de Gustavo González Galindo.
Media, en la que surgieron fenómenos que dieron paso a la formulación de documentos que establecían y garantizaban algunos derechos humanos, como los fueros españoles que eran otorgados por el rey a sus súbditos.
Como recompensa por haber im- pedido o repelido alguna invasión por parte de los moros, o por alguna otra razón similar. Estos privilegios, que se otorgaban en España, constituían verdaderos derechos garantizados, lo cual se debía a que una vez dado el fuero, el rey mismo que lo cedía, estaba obligado a respetarlo. (Herrera, 1993, p. 61)

Estas figuras fueron seguidas de un gran número de compilaciones legales existentes en toda la península, entre la que destacan la Ley de las Siete Partidas. Otros antecedentes europeos menos conocidos fueron "la Magnus Lagaboter Landslov de Noruega, escrita por el obispo Gunner hacia 1275, el Acta Neminem Captivabimus de 1430" (González, 2013, p. 59). Sin embargo, la Carta Magna inglesa de 1215 se distingue de los anteriores por la forma como se obligó al rey Juan I a firmarla, sirviendo de inspiración para que, concluida la Edad Media, en el siglo XVIII surgieran pensadores como Rousseau, Diderot, Voltaire, Montesquieu, entre otros, que desarrollaron doctrinas antropocentristas patrocinadoras del Estado de derecho no intervencionista (Estado gendarme), se acuñó la frase laissez faire, laissez passer, que favoreció la edificación de la corriente liberal individualista, se emitió la trascendental Declaración de los Derechos del Hombre y del Ciudadano de 1789, todo 
en busca de una mejor forma de gobierno para beneficio del pueblo.

Alcanzado, aparentemente, el Estado ideal y la forma de gobierno que deseaban los gobernados, comenzaron a surgir abusos por el exceso de libertad entre ellos, dado que los empresarios más poderosos y terratenientes aniquilaron rápidamente a los más débiles, retrocediendo a una especie de ley de la naturaleza y llegando a la conclusión de que el "tratar igualmente a los desiguales fue el gravísimo error en que incurrió el liberal-individualismo como sistema radical de estructuración jurídica y social del Estado" (Burgoa, 2008, p. 26).

Como consecuencia de la gran desigualdad social ocasionada, surgió otro grupo de pensadores, encabezados por Marx y Engels, que plantearon la ideología socialista en su Manifiesto comunista de 1848, y que consistía, básicamente, en la eliminación de la propiedad privada y la desaparición de clases sociales — solo la obrera subsistiría - dando paso al nacimiento de la corriente colectivista que, a su vez, originó nuevas formas de Estados y gobiernos que se sustentaban en el pensamiento de que "en caso de oposición entre la esfera individual y el ámbito colectivo, es preciso sacrificar al individuo, que no es, para las ideas colectivistas, sino una parte del todo social cuya actividad debe realizarse en beneficio de la sociedad" (Burgoa, 2011, p. 26). Desafortunadamente, y de manera semejante al liberalismo, esta corriente reduccionista también cayó en consecuencias negativas, toda vez que al considerar al individuo como parte de una colectividad y equiparársele como un producto efímero, de escasa o nula importancia, se llegó al extremo de que el Estado era el dueño de todo y ante tal empoderamiento, se retrocedió a un excesivo intervencionismo estatal que reprimió toda libertad individual antes conquistada.

En la época moderna del siglo XX, después de que diversos pueblos experimentaron las doctrinas indicadas, se configuró una tercera vertiente denominada del bien común, que buscó alcanzar un equilibrio entre las anteriores, considerando que deben coexistir tanto la esfera particular como la colectiva del ente social, atendiendo tanto a las pretensiones individuales como a las sociales, sin excluir a ninguna de ellas, sin embargo, para mantener el orden dentro de la sociedad y evitar que degenere en caos, se deben establecer "límites o prohibiciones al ejercicio absoluto de ésta para mantener el orden dentro de la sociedad y preservar los intereses de la misma o de un grupo social determinado" (Burgoa, 2008, p. 39). Como logro y consecuencia jurídica del bien común, se llegó a la etapa de la justicia social, que entraña "una situación que consiste en una síntesis armónica y de respetabilidad recíproca entre los intereses sociales y los intereses particulares del individuo" (Burgoa, 2008, p. 45). Sin la anterior se incurriría en cualquiera de las posturas extremistas referidas, que substancialmente son injustas al marginar los intereses individuales o de grupos mayoritarios de la sociedad.

Con esta ideología moderada, y después de las atrocidades de la Segunda Guerra 
Mundial, los derechos humanos tuvieron un avance vertiginoso, reflejado en su desarrollo doctrinal en el que destacan diversas clasificaciones, como la generacional, en la que se aprecia que en cada generación se fueron ampliando derechos humanos, al grado de reconocer:

Intereses difusos, colectivos, transpersonales o supraindividuales. Esta terminología se emplea para designar a los sujetos a los que el derecho de la tercera generación está destinado a proteger, y aquí nos damos cuenta de que no se trata de un individuo (derechos humanos de la primera generación), tampoco se trata de una clase social (derechos humanos de la segunda generación), sino que aquí, en la "tercera generación", se trata de un grupo humano. (Herrera, 1993, p. 33).

En este sentido, es claro que dentro de los derechos que se fueron reconociendo en cada generación, deben ser tutelados por la administración pública, desplegándose una cascada que ha avanzado más rápido que las políticas gubernamentales, lo que ha ocasionado que, desafortunadamente, el DHBG no haya tenido un desarrollo semejante al de otros derechos humanos, lo que probablemente sea porque generalmente los detentadores del poder han manejado la información con mucho secreto, anulando las posibilidades de rendir cuentas sobre su actividad financiera, entendida como "la actividad que desarrolla el Estado con el objeto de procurarse los medios necesarios para los gastos públicos destinados a la satisfacción de las necesidades pú- blicas y en general a la realización de sus propios fines" (Garza, 1992, p. 5). Lo que se advierte de las incipientes actividades financieras de los pueblos de antaño que se caracterizaban por la prepotencia y arbitrariedad en el manejo de los recursos públicos ${ }^{6}$.

Como consecuencia del avance doctrinal, la mayoría de las sociedades a nivel global han encontrado terrero fértil para implantar sistemas democráticos que, a la fecha, han demostrado ser la mejor forma de gobierno, al no sucumbir en extremismos, llegando a materializarse en documentos de índole internacional, como la Declaración Universal de Derechos Humanos (DUDH) y la Declaración Americana de los Derechos y Deberes del Hombre (DADDH), ambas de 1948, la Convención Americana sobre Derechos Humanos (CADH) de 1969, la Carta de los Derechos Fundamentales de la Unión Europea (CDFUE) del año 2000, entre otros que han servido para la conformación de la mayoría de las constituciones políticas de los actuales Estados.

De este breve recorrido histórico resulta evidente que el ser humano siempre ha buscado un gobierno que le proporcione condiciones idóneas para que todos los miembros de la sociedad puedan desarrollarse con la mayor plenitud permisible, a fin de acercarse lo más posible a una vida digna.

- Para mayor detalle de esas prácticas se recomienda ver las actividades financieras de las sociedades antiguas, en el libro Derecho fiscal mexicano de Gregorio Sánchez León. 


\section{ENDEUDAMIENTO SUBNACIONAL EN MÉXICO}

A pesar de que el Estado tiene la responsabilidad de mantener finanzas públicas sanas que le permitan contar con recursos que se destinen a la satisfacción de diversos derechos humanos, desafortunadamente en poco más de dos décadas se ha observado en México un deterioro de las finanzas públicas a nivel subnacional, consistente en la tendencia creciente del endeudamiento en las entidades federativas que ha llegado a alcanzar niveles que podrían poner en riesgo la sustentabilidad financiera de los gobiernos locales para cumplir sus responsabilidades constitucionales y, en menor medida, también podrían repercutir en la viabilidad y estabilidad macroeconómica a nivel nacional, en caso de que no puedan solventar el servicio de sus deudas.

Esta tendencia ha quedado demostrada a través del incremento vertiginoso de la deuda de los gobiernos estatales, al determinar que "el promedio de la deuda de las entidades federativas respecto de sus Participaciones Federales creció de 64,5 \% en 1994 a 84,0 \% en 2015" (Centro de Estudios de las Finanzas Públicas (CEFP/007/2016), 2016, p. 2). Aunado a lo anterior y con datos más recientes y otros parámetros de medición:

El Registro Público Único a cargo de la Secretaría de Hacienda y Crédito Público (SHCP) muestra que el saldo de las obligaciones financieras inscritas se ha incrementado en 448 mil 006,1 mdp en términos nominales en los últimos 15 años, al pasar de $116 \mathrm{mil}$
218,4 mdp al cierre de 2002 a 564 mil 224,5 mdp al segundo trimestre de 2017. (Centro de Estudios de las Finanzas Públicas (CEFP/024/2017), 2017, p. 3)

Lo anterior muestra que en términos reales, la tasa de variación del saldo de la deuda subnacional se colocó en 143,6 \%, siendo la tasa media de crecimiento anual de $6,1 \%$, tal y como se muestra en la figura 1.

\subsection{Entidad federativa más endeudada a nivel nacional}

La densidad poblacional es uno de los factores que propician que una EF se endeude. Dentro de los Estados más poblados del país se encuentra la Ciudad de México (CDMX) con 8,9 millones de habitantes, solo después del Estado de México con 16,6 millones de habitantes. Sin embargo, otros factores que también inciden son la producción de la EF, los ingresos de los gobiernos estatales, la débil recaudación local, la indebida planeación en los presupuestos de egresos, entre otros.

A pesar de ser la CDMX la segunda EF más poblada del país, ocupa el primer lugar de endeudamiento, además porque cuenta con otro factor determinante que la catapulta a esa posición, y es el hecho de tener la economía local más grande del país, con \$74.500 mdp al tercer trimestre de 2017 (Centro de Estudios de las Finanzas Públicas (CEFP/035/2017), 2017, p. 4). Como se muestra a continuación en la figura 2: 


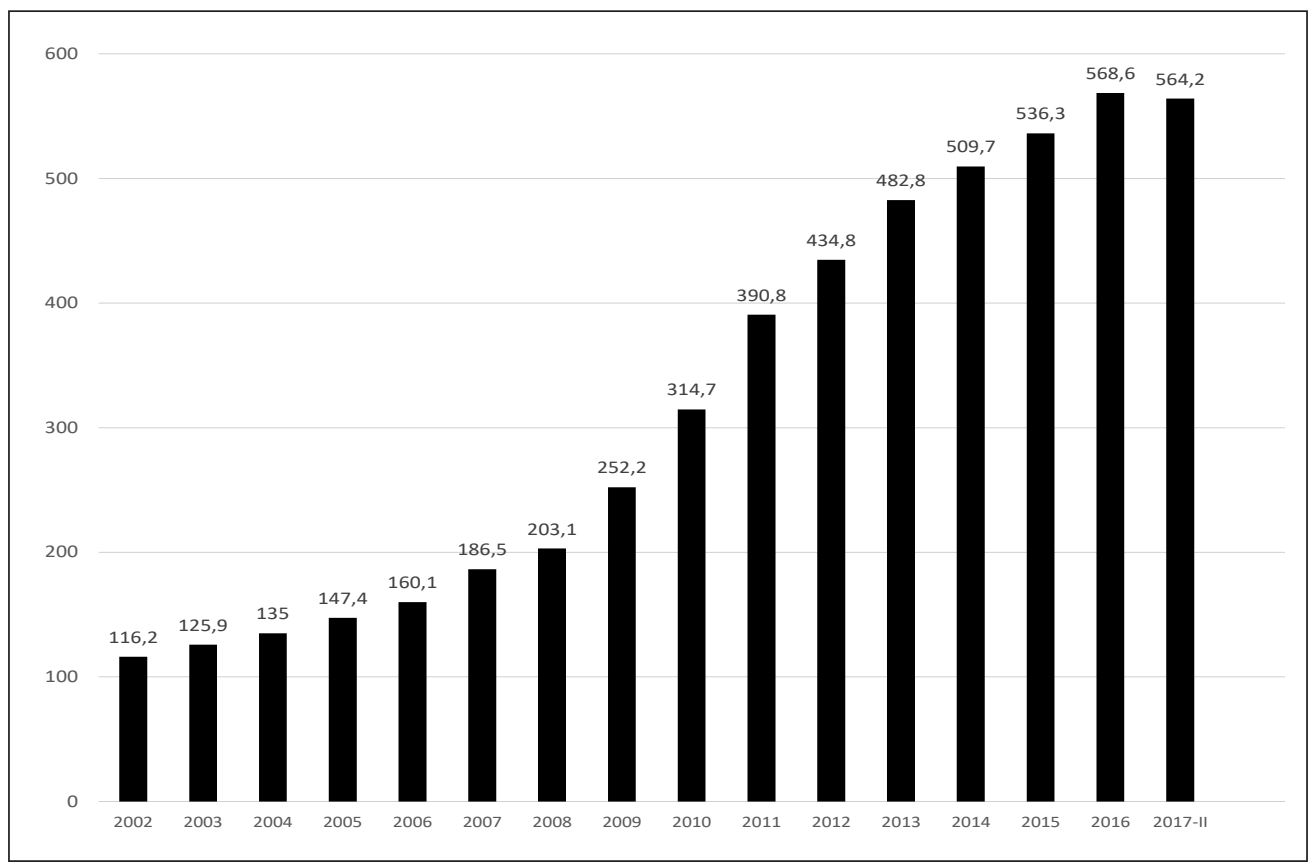

Figura 1. Saldo total de la deuda subnacional 2002-2017/junio Fuente: Centro de Estudios de la Finanzas Públicas

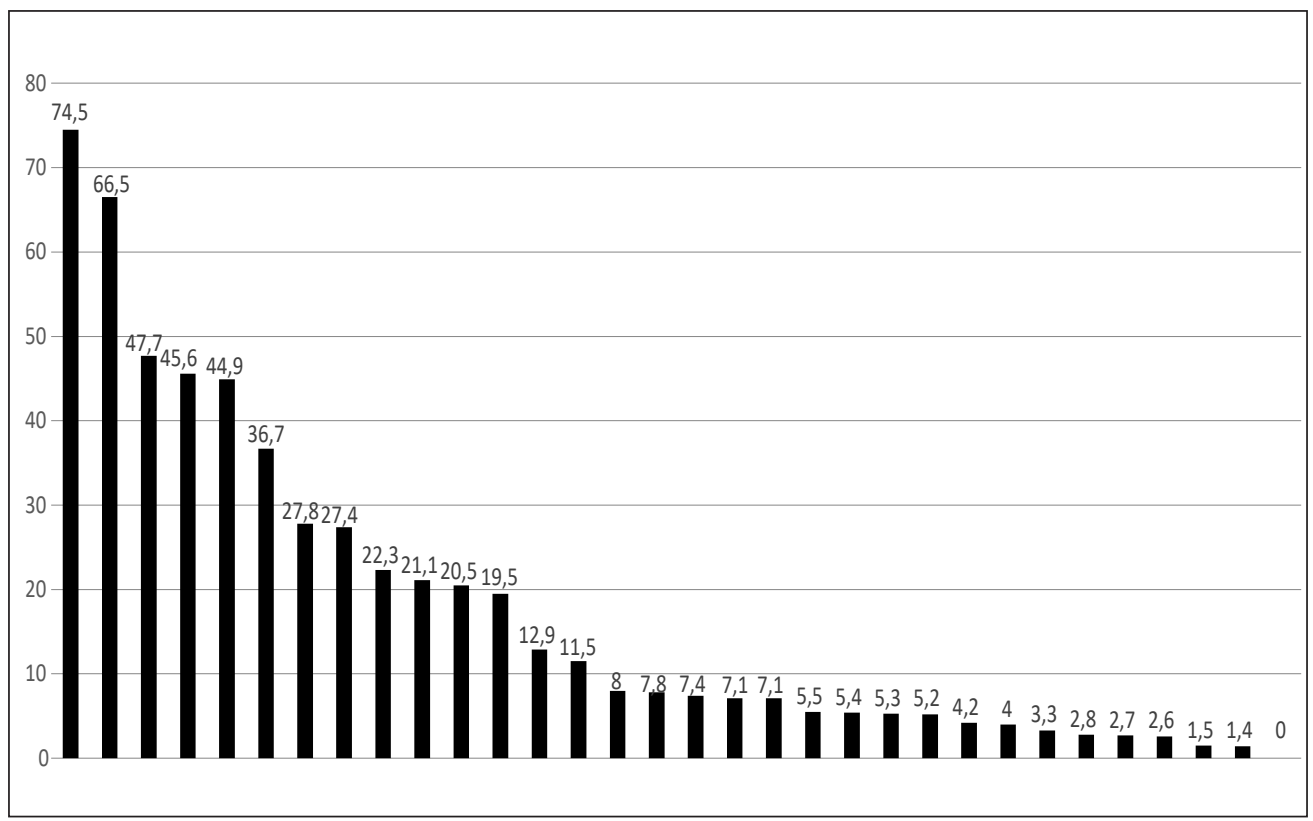

Figura 2. Saldo de la deuda subnacional por entidad federativa, al tercer trimestre de 2017 Fuente: Centro de Estudios de la Finanzas Públicas 
Cabe señalar que la CDMX cuenta con legislación en esta materia, como la Ley de Presupuesto y Gasto Eficiente del Distrito Federal, que tiene como objeto "regular y normar las acciones en materia de programación, presupuestación, aprobación, ejercicio, contabilidad gubernamental, emisión de información financiera, control y evaluación de los ingresos y egresos públicos del Distrito Federal" (Ley de Presupuesto y Gasto Eficiente del Distrito Federal, 2009, p. 1). Otra normatividad más reciente es la Ley de Fiscalización Superior de la Ciudad de México, que tiene como objeto central "regular la fiscalización, organización y atribuciones de la Auditoría Superior de la Ciudad de México; y los actos y procedimientos que realice dentro del ámbito de su competencia dicha Entidad de Fiscalización Superior" (Ley de Fiscalización Superior de la Ciudad de México, 2014, p. 1). No obstante la existencia de estos ordenamientos, ninguno ha servido para frenar el constante y creciente endeudamiento de la CDMX, en razón de que el primero, aún y cuando debería ser más estricto en el tratamiento de los ingresos, no limita la adquisición de deuda pública, en tanto que el segundo no tiene como finalidad regular a priori tal actividad, sino solo auditar a posteriori el destino de los recursos.

En el mismo sentido, la reciente Constitución Política de la Ciudad de México (CPCDMX), ha sido innovadora al establecer una serie de mecanismos específicos para disponer de recursos que logren progresivamente la efectividad de los de- rechos humanos, tal y como se observa en el numeral 5, apartado $A^{7}$ y en el artículo 21 que regula lo relacionado con el funcionamiento de la Hacienda Pública, en la que se deberá planear el destino de los recursos de la CDMX para alcanzar la mayor efectividad de derechos humanos, lo que guarda relación con el numeral 60 que establece el derecho a la buena administración a través de un buen gobierno ${ }^{8}$.

A pesar de los anteriores ordenamientos, cabe destacar que el 27 de abril de 2016 se publicó en el Diario Oficial de la Federación (DOF) la Ley de Disciplina Financiera de las Entidades Federativas y los Municipios (LDFEFM), a fin de controlar el endeudamiento de las finanzas públicas de los gobiernos estatales y municipales, lo que al parecer ha comenzado a conseguir buenos resultados en su breve vigencia, al observar un ligero decrecimiento del endeudamiento, dado que al "tercer trimestre de 2017, el saldo de la deuda sub-

7 Se refiere a una ciudad garantista y específicamente en su apartado A, enfatiza la progresividad de los derechos, entre los que destaca el punto 1, en el que las autoridades adoptarán medidas legislativas, administrativas, judiciales, económicas y las que sean necesarias hasta el máximo de recursos públicos de que dispongan, a fin de lograr progresivamente la plena efectividad de los derechos reconocidos en esta Constitución.

8 La CPCDMX es un documento que entrará en vigor el 17 de septiembre de 2018, establece una gran cantidad de derechos humanos, haciendo énfasis en el derecho a la buena administración a través de un gobierno abierto, integral, honesto, transparente, profesional, eficaz, eficiente y austero, que procure el interés público y combata la corrupción, llegando a cuidar los recursos para garantizar la efectividad de los derechos humanos. 
nacional presenta una ligera reducción de 8 mil 499,5 mdp respecto al año anterior" (Centro de Estudios de las Finanzas Públicas (CEFP/035/2017), 2017, p. 3). La norma tiene por objeto el "establecer los criterios generales de responsabilidad hacendaria y financiera que regirán a las entidades federativas y los municipios, así como a sus respectivos entes públicos, para un manejo sostenible de sus finanzas públicas" (Ley de Disciplina Financiera de las Entidades Federativas y los Municipios, 2016, p. 1). A la par de promover el sano desarrollo de las finanzas públicas a través de la aplicación de los principios de responsabilidad hacendaria, el registro público único (en el que los entes públicos se deben inscribir y transparentar la totalidad de sus obligaciones), el sistema de alertas (que vincula los niveles de endeudamiento, fijando los techos de financiamiento netos anuales) y la contratación de deuda (garantizando que se contrate al menor costo financiero y que el destino sea para inversión pública); se espera que continúe esta tendencia en beneficio de los ciudadanos.

\subsection{Efectos del endeudamiento en la CDMX}

De un somero análisis al creciente endeudamiento de la CDMX, se observan algunas repercusiones a los presupuestos de egresos de los últimos cuatro años de algunas dependencias y entidades, elegidas de conformidad con las necesidades ciudadanas más recurrentes y apremiantes, quedando en los términos que se muestran en la tabla 1.

Con base en la información recabada, en un primer nivel de análisis se advierte que la mayoría de las dependencias y entidades analizadas han tenido un incremento anual en sus presupuestos de egresos, sin embargo, la Secretaría

Tabla 1. Variaciones presupuestales de algunas dependencias de la CDMX

\begin{tabular}{|l|r|r|r|r|}
\hline \multicolumn{1}{|c|}{ Dependencias } & \multicolumn{1}{c|}{2014} & \multicolumn{1}{c|}{2015} & \multicolumn{1}{c|}{2016} & \multicolumn{1}{c|}{2017} \\
\hline Secretaría de Salud & $\$ 6.445 .749 .465$ & $\$ 7.018 .668 .853$ & $\$ 7.417 .791 .650$ & $\$ 7.569 .636 .488$ \\
\hline $\begin{array}{l}\text { Secretaría de } \\
\text { Seguridad Pública }\end{array}$ & $\$ 13.729 .804 .038$ & $\$ 14.390 .693 .151$ & $\$ 15.290 .972 .039$ & $\$ 16.399 .958 .444$ \\
\hline $\begin{array}{l}\text { Secretaría de } \\
\text { Educación }\end{array}$ & $\$ 487.040 .606$ & $\$ 659.721 .636$ & $\$ 823.130 .399$ & $\$ 876.308 .950$ \\
\hline $\begin{array}{l}\text { Secretaría de } \\
\text { Desarrollo Económico }\end{array}$ & $\$ 225.445 .131$ & $\$ 239.016 .899$ & $\$ 311.887 .754$ & $\$ 303.496 .757$ \\
\hline $\begin{array}{l}\text { Secretaría de } \\
\text { Desarrollo Social }\end{array}$ & $\$ 7.976 .551 .777$ & $\$ 8.568 .204 .338$ & $\$ 9.250 .423 .819$ & $\$ 10.284 .013 .273$ \\
\hline Secretaría de Cultura & $\$ 509.774 .750$ & $\$ 577.630 .176$ & $\$ 613.141 .814$ & $\$ 703.726 .737$ \\
\hline Metrobús & $\$ 986.523 .700$ & $\$ 1.394 .734 .640$ & $\$ 1.742 .709 .335$ & $\$ 348.248 .724$ \\
\hline $\begin{array}{l}\text { Sistema de Transporte } \\
\text { Colectivo Metro }\end{array}$ & $\$ 12.900 .265 .083$ & $\$ 15.062 .686 .910$ & $\$ 15.849 .703 .179$ & $\$ 16.473 .051 .402$ \\
\hline
\end{tabular}


de Desarrollo Económico y el metrobús tuvieron una disminución absoluta en sus presupuestos de 2017, consistente en un $2,69 \%$ y $80,02 \%$, respectivamente, lo que seguramente, y con base en un argumento formal deductivo de disminución, ha repercutido negativamente en la realización de sus actividades, dado que cada año aumenta la población y, por ende, sus demandas, teniéndolas que solventar con menos recursos por pasajero. Aunado a lo anterior, en un análisis más detallado se observó con mayor preocupación que los incrementos anuales, en aquellas dependencias que los tuvieron, cada vez han sido en menor proporción, tal y como se muestra en la tabla 2.

De lo anterior resulta evidente concluir que, a pesar de existir un aparente crecimiento en términos absolutos de los presupuestos de la mayoría de las dependencias y entidades, por otro lado, se advierte la disminución en términos relativos anuales a tales presupuestos, es decir, su crecimiento ha sido menor año tras año, teniendo la razonable seguridad, con base en el argumento arriba indicado, de que también ha afectado el desempeño de sus funciones. En este sentido, la tabla anterior muestra que las únicas entidades que tuvieron un incremento anual fueron la Secretaría de Seguridad Pública, la Secretaría de Desarrollo Social y la Secretaría de Cultura, al contrario de las cinco restantes en las que sus incrementos fueron disminuyendo.

\section{METODOLOGÍAS PARA MEDIR LA EFICACIA DE DERECHOS HUMANOS}

Después del largo camino de los derechos humanos para conseguir su reconocimiento, que se ha coronado con su incorporación en diversas cartas magnas y documentos internacionales, se ha llegado a un segundo plano consistente en la necesidad de evaluar su cumplimiento, por lo que desde hace aproximadamente cuatro décadas comenzaron a desarrollar-

Tabla 2. Disminución presupuestal en términos relativos

\begin{tabular}{|l|c|c|c|}
\hline \multicolumn{1}{|c|}{ Dependencias } & $\begin{array}{c}\text { Incremento } \\
2015\end{array}$ & $\begin{array}{c}\text { Incremento } \\
2016\end{array}$ & $\begin{array}{c}\text { Incremento } \\
2017\end{array}$ \\
\hline Secretaría de Salud & $8,89 \%$ & $5,69 \%$ & $2,05 \%$ \\
\hline Secretaría de Seguridad Pública & $4,81 \%$ & $6,26 \%$ & $7,25 \%$ \\
\hline Secretaría de Educación & $35,46 \%$ & $24,77 \%$ & $6,46 \%$ \\
\hline Secretaría de Desarrollo Económico & $6,02 \%$ & $30,49 \%$ & $-2,69 \%$ \\
\hline Secretaría de Desarrollo Social & $7,42 \%$ & $7,96 \%$ & $11,17 \%$ \\
\hline Secretaría de Cultura & $13,31 \%$ & $6,15 \%$ & $14,77 \%$ \\
\hline Metrobús & $41,38 \%$ & $24,95 \%$ & $-80,02 \%$ \\
\hline Sistema de Transporte Colectivo Metro & $16,76 \%$ & $5,22 \%$ & $3,93 \%$ \\
\hline
\end{tabular}


se métodos de medición de fenómenos sociales, inicialmente con evaluaciones simples sobre líneas de pobreza y, posteriormente, se arribó a la medición del índice de desarrollo humano (IDH) del Programa de Naciones Unidas para el Desarrollo (PNUD) que se considera en la actualidad como el principal reto de los estudiosos de derechos humanos, bajo el entendido de que no sirve de mucho tener reconocidos una gran cantidad de derechos, si no se garantiza su cumplimiento. En este terreno se ha llegado a avanzar, incluso, hasta la medición de conceptos más abstractos como la libertad, la transparencia y la gobernanza, puesto que existe suficiente evidencia de que su deficiente aplicación impacta directa y negativamente en el desarrollo progresivo y eficaz de los derechos humanos que consiste en establecer condiciones que le permitan al ser humano desarrollarse digna e integralmente.

La ONU y la OEA han evolucionado en la implementación de metodologías que evalúen el cumplimiento efectivo de derechos humanos, proponiendo básicamente la formulación de indicadores muy específicos, a través de los que se recopila información, se interpreta y se obtienen resultados. Bajo este contexto, la información recabada sirve para realizar análisis de satisfacción de derechos humanos y llevar un seguimiento de los avances realizados, por lo que particularmente los indicadores ayudan a registrar información de manera eficiente y sirven para dar seguimiento y vigilar los resultados prometidos que, paralelamente, ayudan a los Estados a evaluar sus propios avances a la hora de garantizar el disfrute de derechos humanos. Por otro lado, las metodologías gozan de una importancia particular pues debido a su especificidad, se ha reconocido que el uso de estadísticas generales no es suficiente para dar seguimientos concretos y claros sobre derechos.

\subsection{Metodología del Alto Comisionado de las Naciones Unidas para los Derechos Humanos}

El desarrollo formal de una metodología basada en indicadores de derechos humanos, se originó a partir del requerimiento de organismos internacionales encargados de monitorear el cumplimiento de los tratados en la materia, bajo la convicción de que el desarrollo de indicadores apoyaría para que las acciones gubernamentales fueran más sistemáticas y transparentes, además de permitir la medición de los progresos realizados en periodos de tiempo determinados.

La propuesta metodológica del Alto Comisionado de las Naciones Unidas para los Derechos Humanos (ACNUDH) consiste básicamente en plantear un marco teórico conceptual que defina y permita elaborar indicadores que promuevan la vigilancia de derechos Humanos, a efecto de que los indicadores que se seleccionen para cada garantía sean pertinentes de acuerdo al contenido normativo del mismo, esto es, los derechos que se elijan estudiar se deben relacionar previamente en la legislación aplicable para después identificar los atributos que los caracterizan y facilitar la elaboración de indicadores de manera clara, concreta y 
tangible. Posteriormente, y con el objeto de reflejar la complejidad intrínseca de los derechos humanos, se debe contar con una estructura operativa para establecer indicadores que deben ser cuantitativos y cualitativos, donde en los primeros se incluyen los indicadores en sentido estricto como equivalente de "estadísticas", mientras que en la segunda figura toda información articulada de forma descriptiva o "categórica". De manera paralela, la metodología propone prever la medición del compromiso de las entidades responsables respecto a las normas de derechos humanos, los esfuerzos emprendidos para hacer realidad ese compromiso y los resultados de esos esfuerzos en el tiempo, lo que se traduce en una configuración de indicadores estructurales, de proceso y de resultados, respectivamente (ACNUDH, 2012).

\subsection{Metodología de la Comisión Interamericana de Derechos Humanos de la Organización de los Estados Americanos}

Tomando como base la metodología propuesta por el ACNUDH, la Comisión Interamericana de Derechos Humanos (CIDH) de la OEA, que tiene como función principal el promover la observancia y defensa de los derechos humanos (Convención Americana sobre Derechos Humanos, 1969, p. 18), emitió los Lineamientos para la elaboración de indicadores de progreso en materia de derechos económicos, sociales y culturales, donde se plantea un método para la formulación de indicadores para evaluar la satisfacción de derechos humanos. Sin ánimo de ser repetitivo, esta metodología retoma substancialmente las propuestas del ACNUDH, consistente en la formulación de indicadores de estructura, de proceso y de resultados, destacando que esta metodología está diseñada específicamente para DESC, los que deberán sustentarse en el principio de progresividad, entendiendo que por su naturaleza no pueden alcanzarse rápidamente y requieren de un proceso que lleva tiempo, por lo que descalifica la inacción y las medidas regresivas, salvo casos de extremos justiciables (CIDH, 2008).

De manera particular, la CIDH, a fin de mejorar la posibilidad de análisis y organizar de manera más ajustada la información obtenida durante el proceso basado en los indicadores referidos, sugiere que la información deberá responder a tres categorías, comenzando con la recepción del derecho que consiste en el sistema legal, el aparato institucional y las políticas públicas; continuando con las capacidades estatales, que deberán describir el aspecto técnico instrumental y de distribución de recursos y, finalmente, con el contexto financiero y el compromiso presupuestario, que alude a la disponibilidad efectiva de recursos del Estado para ejecutar el gasto público social y la manera de distribución (CIDH, 2008). Bajo este tenor, también sugiere que se responda a los temas transversales de igualdad y no discriminación, facilidades de acceso a la justicia, además del acceso a la información y la participación.

\section{INDICADORES PARA EL DHBG EN LA CDMX}

Los indicadores de derechos humanos tienen múltiples posibilidades de uso: 
como instrumentos eficaces para formular políticas y vigilar procesos, determinar efectos no deseados de leyes y prácticas, identificar a los actores que influyen en la realización de los derechos y si cumplen sus obligaciones, anticipar posibles violaciones y adoptar medidas preventivas, etc. En todo caso "la finalidad de los indicadores es pues, y muy resumidamente, suministrar información relevante en relación con la eficacia de las normas que han de ver con los derechos humanos" (García, 2011, p. 191).

Bajo este orden de ideas, el objeto de esta investigación se ha concentrado en el análisis del DHBG, considerando también el derecho humano a una buena administración pública (DHBAP), pero como esta actividad es tan amplia, fue necesario delimitarla a la actividad financiera y, específicamente, a la presupuestaria, en razón de que, para que el gobierno pueda llevar a cabo las actividades que tiene encomendadas, entre los que debe satisfacer DESC, requiere como premisa básica contar con recursos suficientes, pues de lo contrario será muy difícil que lo haga con pocos recursos y buenas intenciones, o en el mejor de los casos, lo haría de manera muy deficiente, como suele suceder.

El endeudamiento es un problema que presupone una condición contraria a las finanzas públicas sanas y, por ende, una ineficaz administración pública, puesto que, al existir deuda es muy probable que se restrinjan y disminuyan los presupuestos asignados a determinadas funciones, como se advirtió en el análisis realizado a los presupuestos de egresos del $2014 \mathrm{al}$ 2017 de la CDMX, realizado anteriormente en el punto 2.2. en el que se observó que el metrobús fue la entidad más afectada, primero al tener disminuciones anuales constantes, así como la disminución del $80 \%$ de su presupuesto inmediato anterior en 2017, por lo que a continuación se procede a desarrollar el marco teórico que permitirá proponer algunos indicadores.

\subsection{Marco teórico y atributos de los derechos a una buena administración pública y de circulación}

De conformidad con la metodología del ACNUDH, el marco teórico conceptual debe precisar y permitir elaborar indicadores que promuevan la vigilancia de derechos humanos, previa selección de cada derecho de acuerdo a su contenido normativo, lo que servirá para definir indicadores específicos que ayuden a evaluar en qué medida afecta el endeudamiento a la disminución presupuestaria y, en consecuencia, la satisfacción del derecho humano a la circulación por medio del metrobús.

A nivel internacional se ha generado un marco normativo que ha servido de base para que los Estados generen sus propias legislaciones tendientes a regular los DHBG y DHBAP, encabezando la lista la DUDH que en su artículo 22 establece:
Toda persona, como miembro de la sociedad, tiene derecho a la seguridad social, y a obtener, mediante el esfuerzo nacional y la cooperación internacional, habida cuenta de la organización y los recursos de cada Estado, la 
satisfacción de los derechos económicos, sociales y culturales, indispensables a su dignidad y al libre desarrollo de su personalidad. (Declaración Universal de Derechos Humanos, 1948, p. 6)

De lo anterior se advierte que, previo a que cada Estado establezca las condiciones que le faciliten satisfacer los DESC de su población, debe contar con los recursos económicos que se lo permitan, para lo cual es necesario, e incluso indispensable, que tenga una correcta organización y sana administración en sus finanzas públicas.

Siguiendo la disposición anterior, la OEA, que dentro de sus fines también contempla el promover y defender derechos humanos, en la CADH establece en su artículo 26:

Los Estados Partes se comprometen a adoptar providencias, tanto a nivel interno como mediante la cooperación internacional, especialmente económica y técnica, para lograr progresivamente la plena efectividad de los derechos que se derivan de las normas económicas, sociales y sobre educación, ciencia y cultura, contenidas en la Carta de la Organización de los Estados Americanos, reformada por el Protocolo de Buenos Aires, en la medida de los recursos disponibles, por vía legislativa u otros medios apropiados. (Convención Americana sobre Derechos Humanos, 1969, p. 14)

Este artículo logró incorporar dos aspectos importantes: por un lado la figura de la efectividad de los derechos y por el otro, que los Estados cuenten con recursos, en razón de que sin estos es muy difícil que se puedan establecer las condiciones necesarias que permitan alcanzar progresivamente su efectividad, siendo estas aportaciones muy pertinentes, ya que de nada sirve que se encuentre reconocido este derecho en tan importantes documentos si no se establecen los elementos indispensables para su cumplimiento.

En México se encuentra establecido en el artículo 25 de la Constitución Política de los Estados Unidos Mexicanos (CPEUM), lo más cercano al DHBG, al determinar medularmente que:

\section{Corresponde al Estado la recto- ría del desarrollo nacional para garantizar que éste sea integral y sustentable, (...) El Estado velará por la estabilidad de las finanzas públicas y del sistema finan- ciero para coadyuvar a generar condiciones favorables para el crecimiento económico y el em- pleo. (Constitución Política de los Estados Unidos Mexicanos, 1917, p. 23)}

De manera particular en la legislación aplicable a la CDMX, se encuentra el artículo $5^{\circ}$, apartado A, punto 1 de la CPCDMX, que dispone que "las autoridades adoptarán medidas legislativas, administrativas, judiciales, económicas y las que sean necesarias hasta el máximo de recursos públicos de que dispongan, a fin de lograr progresivamente la plena efectividad de los derechos reconocidos en esta Constitución" (Constitución Política de la Ciudad de México, 2017, p. 5). Señala, además, en 
el punto 2 del mismo numeral, que:

El Instituto de Planeación Democrática y Prospectiva de la Ciudad de México establecerá un sistema de indicadores de estos derechos que permitan fijar metas en el presupuesto anual y evaluar la garantía de su cumplimiento progresivo, tomando como base los niveles esenciales y alcanzados de satisfacción conforme a lo previsto por la ley. (Constitución Política de la Ciudad de México, 2017, p. 6)

Al respecto, es de señalarse que este precepto contempla un gran avance al establecer esta obligación, pero desafortunadamente este ordenamiento entrará en vigor hasta el próximo 17 de septiembre de 2018, aunado a que a partir de esa fecha comenzarán los trabajos de elaboración de indicadores, por lo que no se tendrán estos por un largo periodo de tiempo. A mayor abundamiento este ordenamiento de manera puntual establece en su artículo 7.1. que:

Toda persona tiene derecho a una buena administración pública, de carácter receptivo, eficaz y eficiente, así como a recibir servicios públicos de conformidad con los principios de generalidad, uniformidad, regularidad, continuidad, calidad y uso de las tecnologías de la información y la comunicación" (Constitución Política de la Ciudad de México, 2017, p. 8)

De manera particular, el derecho a la circulación, se encuentra de manera genérica en el artículo 13.1 de la DUDH, al establecer que "toda persona tiene derecho a circular libremente y a elegir su residencia en el territorio de un Estado" (Declaración Universal de Derechos Humanos, 1948, p. 4). En tanto que en el artículo 22.1 de la CADH, se dispone que "toda persona que se halle legalmente en el territorio de un Estado tiene derecho a circular por el mismo y, a residir en él con sujeción a las disposiciones legales" (Convención Americana sobre Derechos Humanos, 1969, p. 12).

A nivel nacional, el derecho a la circulación se encuentra consagrado en el artículo 11, al disponer que "toda persona tiene derecho para entrar en la República, salir de ella, viajar por su territorio y mudar de residencia, sin necesidad de carta de seguridad, pasaporte, salvoconducto u otros requisitos semejantes" (Constitución Política de los Estados Unidos Mexicanos, 1917, p. 12). Particularmente en el artículo 13, apartado E, punto 1, de la CPCDMX, se advierte este derecho fundamental al disponer que "toda persona tiene derecho a la movilidad en condiciones de seguridad, accesibilidad, comodidad, eficiencia, calidad e igualdad". Vale la pena subrayar que en el punto 2 del precepto anterior, se establece muy aplicable para el caso del metrobús, que:

Las autoridades adoptarán las medidas necesarias para garantizar el ejercicio de este derecho, particularmente en el uso equitativo del espacio vial y la conformación de un sistema integrado de transporte público, impulsando el transporte de bajas emisiones contaminantes, 
respetando en todo momento los derechos de los usuarios más vulnerables de la vía, el cual será adecuado a las necesidades sociales y ambientales de la ciudad. (Constitución Política de la Ciudad de México, 2017, p. 24).

Derivado de las anteriores disposiciones, en el tramo más cercano a la realización de este derecho, se encuentra la Ley de Movilidad del Distrito Federal, que en su numeral $6^{\circ}$ dispone: "la Administración Pública proporcionará los medios necesarios para que las personas puedan elegir libremente la forma de trasladarse a fin de acceder a los bienes, servicios y oportunidades que ofrece la Ciudad" (Ley de Movilidad del Distrito Federal, 2014, p. 3). Además, existen otros artículos que establecen las atribuciones y obligaciones de las autoridades, de lo que se colige que todas las personas tienen la libertad de circular y trasladarse libremente por el territorio de un Estado, para lo cual este debe proporcionar los medios idóneos para ello, como lo son las vías, calles, carreteras, puentes, así como los medios de transporte que mayor beneficio proporcionen a la sociedad, siendo en la especie el metrobús.

\subsection{Formulación de indicadores}

Con base en la metodología del ACNUDH, y habiendo advertido que existen suficientes fuentes legislativas que sustentan los derechos que nos ocupan, que a su vez sirven de guía para proponer los indicadores que suministrarán la información para evaluar la eficacia de estos derechos; sin ser la intención de este artículo realizar un estudio exhaustivo que establezca los indicadores que deberá desarrollar y aplicar el Instituto de Planeación Democrática y Prospectiva de la Ciudad de México, dado que existe información que solo conocen las autoridades y dependencias involucradas; en este sentido, el presente documento se limita a realizar un mero ejercicio y propuesta de los indicadores que podrán servir al instituto, considerando que el desarrollo de indicadores es novedoso en la actualidad, aunado a que resultaría demasiado vanidoso plantear los indicadores que dicha dependencia tomará en consideración. Bajo este orden de ideas, los indicadores no están validados, dado que son propuestas que en su momento se deberán aplicar, aunado a que la propia CPCDMX todavía no ha entrado en vigor, de donde resulta pertinente e innovadora la elaboración del presente trabajo.

\subsubsection{Indicadores estructurales}

- Tratados internacionales relativos a la satisfacción de DESC.

- Tratados internacionales en materia de movilidad ciudadana y transporte público.

- Tratados internacionales relativos a la progresividad efectividad de derechos humanos.

- Fecha de entrada en vigor y cobertura del derecho humano a una buena administración gubernamental.

- Fecha de entrada en vigor y cobertura del artículo 25 constitucional, relativo a la estabilidad de las finanzas públi- 
cas y del sistema financiero.

- Legislación aplicable a la CDMX relativa al derecho a una buena administración pública.

- Fecha de entrada en vigor y cobertura del derecho humano a una administración pública.

- Legislación aplicable a la CDMX correspondiente al derecho a la libre circulación y transporte público.

- Fecha de entrada en vigor y cobertura del derecho humano a la circulación y transporte público.

- Legislación aplicable a la CDMX en la que se adopten medidas para la máxima efectividad de los derechos.

- Legislación reglamentaria del artículo 7.1. de la CPCDMX, relativa al derecho a una buena administración pública.

- Legislación reglamentaria del artículo $5^{\circ}$, apartado A, punto 2 de la CPCDMX, que dispone el establecimiento de un sistema de indicadores de derechos que permitan fijar metas en el presupuesto anual y evaluar la garantía de su cumplimiento progresivo.

- Fecha de entrada en vigor y cobertura del sistema de indicadores de derechos correspondientes a las metas en el presupuesto anual.

- Legislación reglamentaria del artículo 13, apartado E, punto 1, de la CPCDMX, correspondiente al derecho a la movilidad en condiciones de seguridad, accesibilidad, comodidad, eficiencia, calidad e igualdad.
- Medias adoptadas por las autoridades para garantizar el derecho a la movilidad, de conformidad con el artículo 13, apartado E, punto 2 de la CPCDMX.

- Medios proporcionados por el gobierno de la CDMX, para que las personas elijan libremente la forma de trasladarse a fin de acceder a los bienes, servicios y oportunidades que ofrece la ciudad, de conformidad con el numeral $6^{\circ}$ de la Ley de Movilidad del Distrito Federal.

\subsubsection{Indicadores de proceso}

- Proporción de usuarios del metrobús en la CDMX.

- Ingreso per cápita mensual y anual, por sexo, edad y actividad.

- Gasto per cápita mensual y anual de transporte por zonas geográficas.

- Implementación de políticas o programas para la mayor cobertura del servicio de metrobús.

- Proporción de presupuesto asignado anualmente para el servicio de metrobús.

- Ampliación anual de las rutas de circulación.

- Existencia y alcance de acciones para usuarios menores de edad y en condiciones de discapacidad.

- Existencia y número de oficinas o medios de información y quejas de usuarios.

- Existencia de medidas de seguridad en los vehículos de metrobús. 
- Número de demandas o quejas realizadas por usuarios del metrobús en materia de discriminación, tarifas y acceso.

\subsubsection{Indicadores de resultados}

- Proporción de la población que requiere usar el metrobús.

- Proporción de personas que no tienen acceso al metrobús.

- Proporción de personas que han dejado de usar el metrobús por falta de cobertura.

- Porcentaje de personas con alguna discapacidad que dejaron de usar el metrobús.

- Porcentaje de personas que dejaron de usar el metrobús por falta de cobertura.

- Porcentaje de personas que dejaron de usar el metrobús por no contar con recursos suficientes para su pago.

- Proporción de crecimiento anual de la población usuaria del metrobús en la CDMX.

- Proporción de crecimiento anual de las líneas del metrobús.

- Incremento del costo de pasaje del metrobús.

- Proporción de subsidio anual para el metrobús.

\section{CONCLUSIONES}

Resulta innegable que el buen gobierno y la buena administración son derechos hu- manos que tienen una tradición inmemorial, que desde los tiempos más remotos el ser humano se unió con otros semejantes para alcanzar objetivos comunes de sobrevivencia, al grado que en la actualidad se encuentran consagrados en diversos ordenamientos tanto internacionales como nacionales, sin embargo, dentro de esta larga trayectoria los gobiernos no se acostumbraron a rendir cuentas sobre sus actos, incluyendo las finanzas públicas.

En tal virtud, los Estados no desarrollaron el DHBG, dedicándose a reconocer paulatinamente a lo largo del avance de la humanidad otros derechos humanos, lo que se ha identificado como una primera etapa de florecimiento de aquellos, pero fue hasta finales del siglo XX, que habiéndose reconocido un gran número de derechos humanos por la mayoría de los Estados, que se pasó a una segunda etapa, caracterizada por el hartazgo de que no se cumplieran los mismos, por lo que las sociedades comenzaron a cuestionar su eficacia.

Ante tales sucesos, diversos organismos internacionales protectores de derechos humanos, fueron los primeros que propusieron metodologías para la medición del cumplimiento de derechos, sustentados básicamente en la creación de indicadores.

El problema que motivó esta investigación es que los Estados tienen cada vez más deuda, lo que constituye, en principio, una evidente falta de responsabilidad gubernamental en el buen manejo de la administración financiera estatal, que tiene 
como resultado unas finanzas no sanas, que no cumplen ni satisfacen el DHBG.

En este sentido, dentro de los indicadores propuestos por los organismos internacionales no se advierten indicadores para la medición del DHBG, que a pesar de que existieran, se deben desarrollar y adecuar a cada gobierno en particular, puesto que cada uno tiene condiciones específicas que varían por sus diversas sociedades, economías, leyes, etc.

En el presente trabajo se desarrollaron algunos indicadores para medir el servicio a la circulación, específicamente al transporte proporcionado por el metrobús en la CDMX, en atención a que es la EF más endeudada y la segunda más poblada del país, por lo que al observar que el transporte público es una de las necesidades más requeridas de la población, aunado a su disminución presupuestal, se tomó como objeto de estudio y se propusieron indicadores para observar si la deuda pública que disminuyó el presupuesto asignado a ese servicio, impactó en la cobertura y calidad del servicio.

Con base en lo anterior y en los análisis realizados en el trabajo, se observó que, a pesar de existir un aparente crecimiento en términos absolutos a los presupuestos de la mayoría de las dependencias y entidades de la CDMX, se advirtió una disminución en términos relativos anuales a tales presupuestos, es decir, su crecimiento fue menor año tras año, lo que seguramente ha afectado el desempeño de sus funciones y satisfacción de DESC, y particularmente en el derecho de cir- culación a través del metrobús, que fue la entidad más afectada en los últimos cuatro años analizados.

Cabe señalar que, aunque en este trabajo solo se propusieron los indicadores que podrán utilizarse para evaluar el desempeño del DHBG, desde la función particular del metrobús, servirán de antecedente para la elaboración de otros trabajos de investigación, dado que la CPCDMX establece en su artículo $5^{\circ}$, apartado A, punto 2, que se deberán formular indicadores; por lo que estas propuestas ya se consideran un avance que seguramente servirán como modelo para otros Estados.

El objetivo propuesto se cumplió al observar que, al existir deuda, se impactó directamente en el presupuesto de la mayoría de las entidades, lo que seguramente también impactará negativamente en la satisfacción de derechos, por lo que en este sentido, la deuda pública excesiva es un factor de ineficacia del DHBG, al no contarse con recursos suficientes para satisfacer otros derechos humanos, sirviendo como caso de estudio el derecho a la circulación por medio del metrobús en la CDMX.

\section{REFERENCIAS}

Burgoa, I. (2008). Las garantías individuales. Ciudad de México: Porrúa.

Centro de Estudios de las Finanzas Públicas. (2016). Diagnóstico de la deuda pública de las entidades federativas (CEFP/007/2016). Recuperado de http://www.cefp.gob.mx/publicaciones/ documento/2016/abril/cefp0072016.pdf 
Centro de Estudios de las Finanzas Públicas. (2017). Obligaciones financieras de las entidades federativas de Ciudad de México, al segundo trimestre de 2017 (CEFP/024/2017). Recuperado de http://www.cefp.gob.mx/publicaciones/ documento/2017/cefp0242017.pdf

Centro de Estudios de las Finanzas Públicas. (2017). Obligaciones financieras de las entidades federativas de Ciudad de México, al tercer trimestre de 2017 (CEFP/035/2017). Recuperado de http://www.cefp.gob.mx/publicaciones/documento/2017/cefp0352017.pdf

Constitución Política de la Ciudad de México.

Constitución Política de los Estados Unidos Mexicanos.

García, J. (2011). ¿Qué es un indicador de derechos humanos y cómo se utiliza? Derechos y Libertades, (24), 179-219. Recuperado de https://core.ac.uk/download/pdf/29403784. $\underline{\mathrm{pdf}}$

Garza, F. (1992). Derecho financiero mexicano. Ciudad de México: Porrúa.

González, G. (2013). La ponderación de los derechos fundamentales. Ciudad de México: Porrúa

Herrera, M. (1993). Manual de derechos humanos. Ciudad de México: Pac.

Ley de Disciplina Financiera de las Entidades Federativas y los Municipios. (2016). Recuperado de http://www.diputados.gob. mx/LeyesBiblio/pdf/LDFEFM_300118.pdf

Ley de Fiscalización Superior de la Ciudad de Ciudad de México. (2014). Recuperado de http://www.aldf.gob.mx/archivo-e4e8175b286e0b531239707bf9626440.pdf
Ley de Movilidad del Distrito Federal. (2014). Recuperado de http://www.aldf.gob.mx/archivo-0d18785faa7af50882d58a18661c6ad7. $\underline{\mathrm{pdf}}$

Ley de Presupuesto y Gasto Eficiente del Distrito Federal. (2009). Recuperado de http://www.aldf.gob.mx/archivo-dca801f8c$\underline{\text { b48ec67dld652cb16ddc697.pdf }}$

Locke, J. (2005). Ensayo sobre el gobierno civil. Ciudad de México: Porrúa.

Organización de los Estados Americanos (OEA). (1969). Convención Americana sobre derechos humanos. Recuperado de https://www. oas.org/dil/esp/tratados_b-32_convencion_americana_sobre_derechos humanos.htm

Organización de las Naciones Unidas (ONU). (1948). Declaración Universal de Derechos Humanos. Recuperado de http://www. ohchr.org/EN/UDHR/Documents/UDHR Translations/spn.pdf

Peces-Barba, G. (1999). Curso de derechos fundamentales. Teoría general. Madrid: Universidad Carlos III de Madrid-Boletín Oficial del Estado.

Porrúa, F. (1990). Teoría del Estado. Ciudad de México: Porrúa.

Rousseau, J. (2006). El contrato social. Ciudad de México: Porrúa. 